\title{
Cause of Reduction of Effective Roadway Width Due to Side Friction in Dhaka City
}

\author{
Md. Mofizul Islam ${ }^{1}$, Md. Shamim Al Razib ${ }^{2}$, Md. Mahmudul Hasan ${ }^{2}$, Md. Shapon Ali ${ }^{1}$, \\ Md. Ohab Monir ${ }^{1}$, Md. Hasan ${ }^{1}$ \\ ${ }^{1}$ Department of Civil Engineering, World University of Bangladesh, Dhaka, Bangladesh \\ ${ }^{2}$ Department of Civil Engineering, Rajshahi University of Engineering \& Technology, Rajshahi, Bangladesh \\ Email address: \\ shamimrazib.ruet@gmail.com(Md.S.Al Razib),mh.rase175@gmail.com(Md.M. Hasan)
}

\section{To cite this article:}

Md. Mofizul Islam, Md. Shamim Al Razib, Md. Mahmudul Hasan, Md. Shapon Ali, Md. Ohab Monir, Md. Hasan. Cause of Reduction of Effective Roadway Width Due to Side Friction in Dhaka City. American Journal of Traffic and Transportation Engineering. Vol. 3, No. 1, 2018, pp. 6-17. doi: 10.11648/j.ajtte.20180301.12

Received: February 24, 2018; Accepted: March 21, 2018; Published: April 26, 2018

\begin{abstract}
Reduction of effective road width is a common problem in everywhere of the world and in Dhaka city; it's a major problem for its huge traffic volume. This study includes an investigation to find out the cause of reduction of effective roadway width due to side friction is Dhaka city. The specific objectives of the study were to identify the factors which contribute in the Reduction of roadway width for measure the total wide loss. Reduction of roadway width due to side friction is a major problem for the people transport system. The pedestrian face many problem to walk on footpath due to site friction. When footpath is blocked for various side friction likes tea stall, shirt pant stall, paper stall, Fruit stall etc. the pedestrian tense to effective roadway width for that reason traffic jam occurs. For rapid economic, industrial and cultural growth of any county a good system of transportation is very important. As transportation comprise road ways, railways, waterways, and airways mankind has to think of a convenient and easy way for movements and this may probably be the beginning of modern roads since roadway can be width and free from side friction.
\end{abstract}

Keywords: Effective Roadway, Side Friction, Dhaka City, Parking, Road Capacity, Transportation System

\section{Introduction}

Dhaka is the capital and largest city of Bangladesh. Today it has grown into a mega city of about 8.5 million people, with an area of about $1353 \mathrm{sq} . \mathrm{km}$. becoming the hub of the nation's industrial, commercial, cultural, educational and political activities. The city has a growing middle class population, driving the market for modern consumer and luxury goods. The city has historically attracted a large number of migrant workers such as hawkers, peddlers, small shoppers, rickshaw transporters, roadside vendors and stalls employ a large segment of the population - rickshawdrivers alone number as many as 400,000. Half the workforce is employed in household and unorganized labor, while about 800,000 work in the textile industry. Even so, unemployment remains high at $23 \%$. As of 2009, Dhaka's Gross Municipal Product (GMP) is registered at $\$ 81$ billion. With an annual growth rate of $6.2 \%$, the GMP is projected to rise to $\$ 215$ billion by 2025 . The population of this megacity is estimated to be 15.69 million by 2016 (DMDP, 1995). As per future prediction, this population will further grow to about 20 million by the year 2020 and to 25 million by 2025 [4].

The city experiences the proliferation of scattered development without appropriate guidance which resulted in huge urban system difficulties. Transportation system is one of the burning questions in the city. Transportation system is the engine of the economic activities in all urban communities, and consequently sustains livelihood of the people living in them. Typical urban transportation facilities in Dhaka city include railways, waterways, airways and roads. Among these, the big proportion consists of roads. Logically, most planning and research efforts have focused on the road system $[9,10]$. In developing countries roadway length is too little compare to developed country. Due to the increase of economic development number of traffic and vehicles increase rapidly. Besides unauthorized retail activities on or besides the road is frequent. They occupy the 
road way width. Also due to lack of off-street parking on street parking is increasing which leads capacity reduction of roadway. Consequence is traffic congestion at peak hour. Besides number of side friction and illegal activity on the road hampered free flow of traffic [2, 3].

The main objectives of the research are to identify the factors which contribute in the reduction of roadway width, to categorize the factors into several groups and also to find the average effective width loss due to side friction. It is expected that the outcome of this research will help city authorities, policy makers as well as Professionals to realize the contribution of side frictions at traffic flow and to take appropriate policy for improving the current deteriorating situation and to make it a livable city.

The study focuses on the present condition of Dhaka city. But due to diverse constraints it's not possible to identify all the side frictions of whole Dhaka city road network. The study is performed only for the commercial areas of Dhaka city. To carry out this tentatively four major roads are taken from commercial areas. The roads are Motijheel to Dainik Bangla, New market to Science lab, Arambag to Fakirapool and Kakrail to Malibag.

This research is essentially about the identification of various types of side friction and their contribution to reduce effective width of road as well as roadway capacity. Various activities cause side frictions such as pedestrian activity, parking, non-motorized vehicles, bicycles and so on. An extensive literature review is carried out to get the basic understanding and to acquire knowledge on particular topics.

There are several other studies identified to have attempted to incorporate and quantify the effects of different frictional elements on road networks of urban areas [1, 7, 8, 14, 15]. Highway capacity manual (HCM) developed by the transportation research board of USA provides some procedure to introduce to Transportation Engineering to determine level of service [17]. It divides the quality of traffic into six levels ranging from level A to level F. Level A represents the best quality of traffic where the driver has the freedom to drive with free flow speed and level $F$ represents the worst quality of traffic. Level of service is defined based on the measure of effectiveness or (MOE). Typically three parameters are used under this and they are speed and travel time, density, and delay. One of the important measures of service quality is the amount of time spent in travel. Though it is widely appreciated that activities at the roadside affect the operation of the traffic stream and may cause delay, there are few references which try to quantify their effects directly especially for developing countries where their effects are likely to be high $[2,6]$. The most usual way in which such effects are incorporated into traffic calculations and procedures is by some kind of proxy classification. Perhaps the most well-known set of procedures for capacity and level of service (LOS) calculations are applied in the U.S. Highway Capacity Manual (HCM 2000), which uses various proxies. Roads designated primarily for access to property are designed and operated in a manner that facilitates access to properties and not movement of traffic [13].
The relevant literatures on transportation system and side frictions from home and abroad that were studied are represented in this chapter. Efforts have been made to describe the different parameter transportation, urban road network, traffic management and operations etc. From the above description, it is evaluated that there are enormous areas, field and branches related to the field and it is very difficult to conduct comprehensive study to identify the inherent weakness. It is also proved from the review of related studies that almost all this topics are interconnected with each other and one is directly affected by others. Al most all of the study focused on a particular area or region like Dhanmondi, Kalabagan, or a particular user group like pedestrian, garments worker etc. or particular operational, management issue like bust service, NMT, travel behavior etc. A comprehensive study is needed comprising all of the major issues.

\section{Description of Study Sites}

\subsection{Traffic Facilities}

Dhaka city mainly depends on road-based transportation system but the amount of road network is far apart from the minimum requirements. Only 9 percent of roadways and 6 percent of pavement area is available, in which $62 \mathrm{~km}$ functional primary and $108 \mathrm{~km}$ secondary and $221 \mathrm{~km}$ connector road serve the city transport service. It is evaluated that bus service plays the dominant role in providing public transport facilities ( $58 \%$ passenger by only $8 \%$ trip) but lack of proper land use and transport planning, uncontrolled development and due to post planning approach; about half of the area do not have the bus service facilities.

\subsection{Weather Conditions}

Weather conditions include various factors such as rain, wind, fog, smoke, clouds, etc. Most of these factors affect speeds and capacities by reducing visibility. In particular rain affects both speed and capacity by reducing visibility and causing a wet road surface. Though rain is sometimes common in Dhaka city, it was avoided by performing the study during the dry season of the year. Traffic data collection in rain would also have been unpredictable and difficult. Measurements were thus made when the road surface was dry.

\subsection{Site Selection}

In the above section, an inventory of traffic facilities and conditions were identified. In this part, specific roads and sites were selected based on those findings. The selection was certainly limited by time constraints. This selection was deemed important because the results based on them were expected to represent the whole commercial areas of Dhaka city.

Firstly, roads were selected based on the presence of a wide range of traffic flow conditions such as flow intensity (volume/capacity ratio), traffic mix, percentage of heavy 
vehicles, and levels of side friction. Secondly, roads were selected based on the area and their physical and geometric quality. While selection of roads was generally based on physical, environmental and traffic conditions, selection of the study sites/segments, was based on more specific requirements, which were specified as; straight alignment, located in a flat terrain, easy to observe side frictions. Based on these, the following roads and sites were selected Mirpur1 to Technical, Technical to Shyamoli, Shyamoli to Asadgate, Asadgate to Dhanmondi27, Dhanmondi27 to Science Lab and Science Lab to New market.

\section{Methodology}

\subsection{Research Design}

Following methods were adopted to achieve the perspective objectives.

i. At the very beginning of the research work an extensive literature review has been conducted to know the conditions, types, nature, limitations, recommendations etc. of previous research, project reports conducted in home and abroad on and transportation system, transport operation and maintenance, institutional setup etc. in Dhaka metropolitan city and to acquire knowledge for the basic understanding on that topic.

ii. Then objectives have been formulated to identify the factors which contribute in the reduction of roadway width and to categorize the factors into several groups.

iii. After that selection of study area which is selected based on the side friction intensity at the site. Considering this commercial area is preferred.

iv. Relevant data which were required to understand the present transportation situation of the Dhaka city were collected from secondary sources like DCC, DUTP, RHD, DMP, BRTA, BRTC, previous research survey report and internet browsing. Relevant data also collected from print media and electric media.

$v$. At the same time of secondary data has been taken field observation and field data taken procedure also started. Both primary and secondary data have been analyzed and manipulated with a view to achieve the objective which is set out in the introductory chapter.

vi. Primary data has been used to identify and categorize the side friction factors also to calculate the reduction of effective roadway width. Whereas secondary data has been used to overview the present Dhaka city condition.

vii.Finally, in line with research findings, the relevant guidelines, policies, regulations have been proposed for realistic and affordable short and long term actions to improve the physical roadway condition.

\subsection{Types and Sources of Data}

As described earlier, in this study, different types of data has been collected from different sources applying different methods and techniques. Major types of data and sources are provided which is given below.

\subsubsection{Primary Data}

a) Field Survey: Overall Observation, Road Inventory Survey, Questionnaire Survey in Different Levels and Sectors, Capturing Photograph

b) Discussion with Professionals/government officials of different relevant organizations

\subsubsection{Secondary Data}

i. Published literature

ii. Survey of Bangladesh (SOB) - Land use, road orientation and transport infrastructure

iii. Dhaka City Corporation - Land use, road functionality, institutional setup,

iv. Rajdhani Unnayan Kartripakka (RAJUK) - Land development, institutional setup

v. Bangladesh Road Transport Authority (BRTA) Vehicle registration, route permit, Institutional management

vi. Print and electronic Media Report- News Magazine; TV, Radio report

vii.Internet browsing - definition, good references/practices, examples

\subsection{Data Collection Period}

For primary data collection, observations and survey were carried out during different days of month and different time of the day in different roads within the year to obtain more representative and authentic data and results. Data has been collected mainly at peak hour to find out all the contributory side frictions on the road. As analysis of side friction factors is new dimension for different transport authorities no secondary data were found related to side friction analysis. However data from media reports, news, views on Dhaka city or internet browsing have been collected continuously entire the study period. Other secondary data like survey report, publications and presentations subsequently collected in different time.

\subsection{Data Collection}

Overall city has been observed to find out an overall view of the study area within the whole study period both in a systematic and random nature. It also gives an outlook to the geographical extent of the city. An overall idea of the present development condition of the study area (CBD, industrial area, residential area, mixed area, fringe area) could also be found through this observation. Existing road network system and the general condition of the roads, organizational and transport integrity of the study area has also been revealed by this observation. The condition of the existing mass transit and services such as operation, management, maintenance, parking, terminal, drainage system, garbage disposal system has also been found in this observation. The conditions of side road, accessibility, road hierarchy, functionality were also enclosed in this survey of different zones of the city [16]. 
To find out the primary data continuous observation has proceeded at the selected sites. Auto meter has been used to measure the roadway length and illegal activities which occupies the road length. A digital camera also used to capture the photograph of different side frictions and roadway condition. Photographs were also used to the analysis at desktop environment. Data has been collected along the roadway in one direction.

\subsection{Analysis Procedure}

First different side frictions were categorized. Also find out the cause of this illegal activity. Percent of loss of effective width is calculated from width occupied by the side frictions and roadway effective width at a particular section of the road. Effective roadway is defined as total carriageway of the road. Percent of loss of effective width can be formulated like as following:

$\%$ Effective width loss $=(\mathrm{d} / \mathrm{D}) * 100 \%$

Here, $d=$ Reduction of effective roadway width due to particular side friction.

$\mathrm{D}=$ Effective roadway width at that particular section.

Assuming there is a linear relationship between effective roadway width and roadway capacity, we can also comment on the reduction of roadway capacity.

\subsection{Limitations of the Data Collection}

A comprehensive and thorough study requires much time and resources. In this study, emphasis has been made on selected areas and parameters in selected field and concentrated on the selected factors related to the side friction. As mentioned earlier that no significant research on this issues had been done so far, so it is often very much difficult to get the necessary reliable information about the present problems and issues. Due to the limitation of time and necessary resources, a small sample survey has been conducted. At this study data has been taken only for commercial area from four different roads. To reflect the overall Dhaka city condition study area should be more.

As there was variety of dimensions in the transportation system as well as associated problems, many of them could not be attended during the study period. So these types of side frictions cant accounted at this study.

\section{Reduction of Roadway Width for Side Friction}

\subsection{Categorization of Side Friction}

Side frictions which are commonly occurred can be categorized like as following:

\section{Parking on the road}

(I) Single parking: (a) Car Parking (b) Auto rickshaw Parking (c) Motorcycle Parking (d) Bus Parking (e) Rickshaw Parking

(II) Double and Triple Parking

3. Different types of stalls: (a) Tea stall (b) Shirt, pant and belt stall (c) Fruit stalls (d) Other stall

4. Scrap of stalls

5. Electric pole on the road

6. Waste and Dustbin

7. Police barricades

8. Roadside cutting activity

Besides following factors are also found on different roads. But there contribution on reduction of effective roadway width is not analyzed due to different constraints.

i. Blockage of the travel way: Public transport vehicle which may stop anywhere to pick up and set down passengers, Pedestrian crossing or moving along the roadway, Non-motorized vehicle which reduce the average speed of the road.

ii. Small Rickshaw Garage on the road

iii. Sidewalk of the people through the roadway

iv. Washing of dishes on the road

\subsection{Parking on the Road}

Parking is essential for business and commercial activities. Efficient parking system provides harmonious vehicular movement. But illegal or uncontrolled parking on the road cause grave inconvenience to road user [5]. In Dhaka Metropolitan city, according to Building Code Regulations provided by RAJUK only basement base parking is mandatory, almost 12 percent of tall building (7+ floor) has not any parking facility. Figure 1 shows the percent of tall building in different thana where has not any parking facility. From figure 1 it is evaluated that old Dhaka like Kotwali and Lalbag thanas' have almost 67 percent and 54 percent tall building which have not any parking lots or facilities. Even, in New Dhaka particularly Mohammadpur and Mirpur where most of the areas are pre-planned, almost one forth tall buildings have not any parking [12].

Among different types of illegal on-street parking following group can be categorized:

Single parking

i. Car Parking

ii. CNG Parking

iii. Motorcycle Parking

iv. Bus Parking

v. Rickshaw parking

Double and triple Parking 


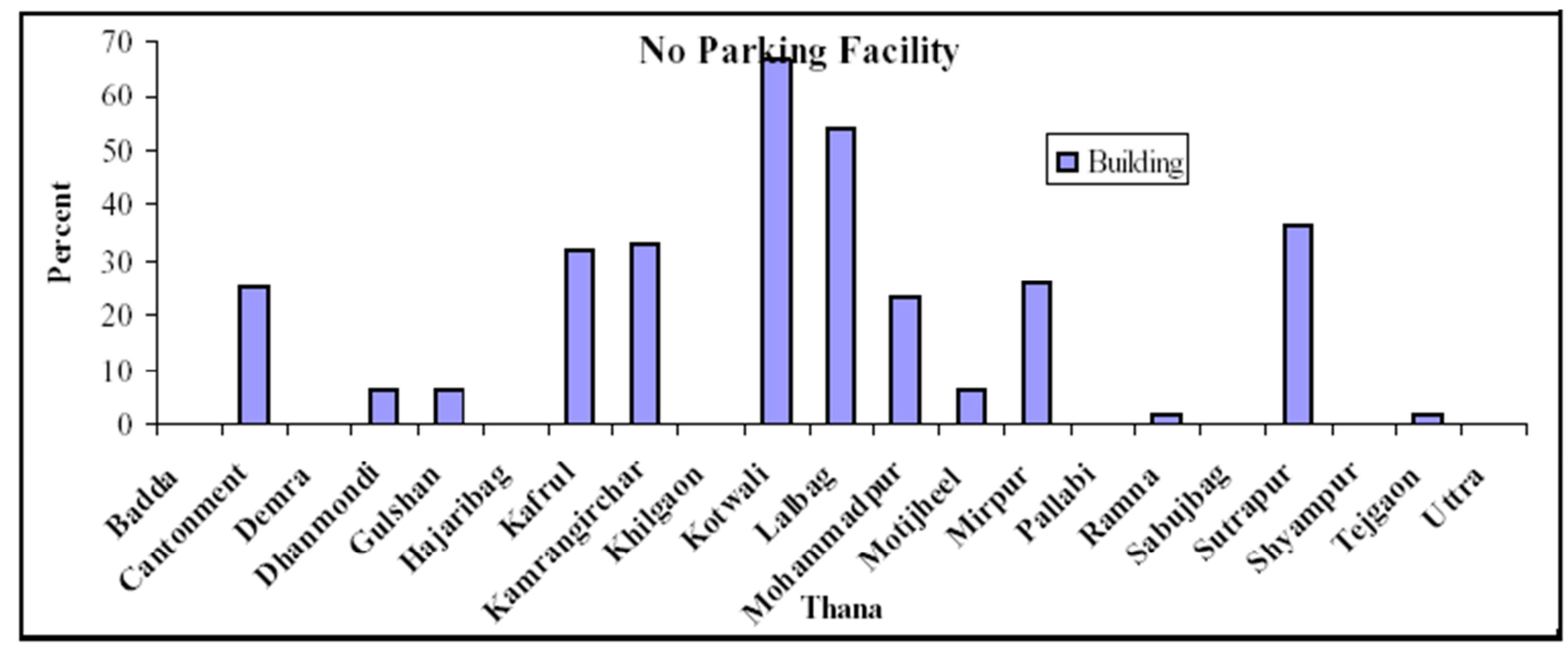

Figure 1. Percent of no parking facility tall building in different Thana.

\subsubsection{Car Parking}

Among a variety of vehicle and traffic modes Private car and Micro bus are one of the common vehicles on Dhaka city road network. Mainly higher class people who like to lead luxurious life use private car for their personal convenience.. With the increase of private car traffic congestion and illegal parking also increased. About all of the roads are experienced with the illegal parking of private car. This is most likely to be occurred at peak hour of the day. Following table 1 indicate amount of effective roadway width loss during the peak hour period at different routes only for illegal on-street parking.

Table 1. Reduction of roadway width for car parking.

\begin{tabular}{lllll}
\hline Route name & Width loss (m) & Total Width (m) & \%Width Loss & Average Width Loss \\
\hline Mirpur 1 -Technical & 4.88 & 12.20 & 40.00 & \\
Technical-Shyamoli & 3.37 & 11.27 & 29.90 & 18.27 \\
Shyamoli - Asadgate & 3.10 & 16.50 & 19.60 & $24.20 \%$ \\
Asadgat - Dhanmondi27 & 3.24 & 16.53 & 13.27 & \\
Dhanmondi27 - New market- & 2.15 & 16.20 & \\
\hline
\end{tabular}

\subsubsection{Auto Rickshaw Parking}

The auto rickshaws are three wheeled mechanically operated vehicles, whose body is generally manufactured locally but the chassis along with the engine is imported from foreign countries. The auto rickshaws carrying capacity is three persons at the back and the driver in the front. They are operated like rickshaws, taking the passengers to their destination and not stopping to pick up other passengers on route. The charge of auto rickshaw is $6 \mathrm{Tk} / \mathrm{km}$ and a minimum flat rate of Tk. 18. Mainly parked auto rickshaws are available in front of market, hospital or bus terminal. Hence due to illegal parking on the road, roadway effective width is reduced consequently reduction in roadway capacity. Reduction in road way effective widths are shown in the following table 2 .

Table 2. Reduction of roadway width for auto-rickshaw.

\begin{tabular}{llll}
\hline Route name & Width loss $(\mathbf{m})$ & Total Width $(\mathbf{m})$ & \% Width Loss \\
\hline Mirpur 1 -Technical & 2.90 & 12.20 & 23.77 \\
Technical- shyamoli & 1.52 & 11.27 & 13.48 \\
Shyamoli - Asadgate & 1.87 & 16.50 & 11.33 \\
Asadgate - Dhanmondi27 & 1.80 & 16.53 & 10.88 \\
Dhanmondi 27 - New market & 3.28 & 16.20 & 20.24 \\
\hline
\end{tabular}

\subsubsection{Motorcycle Parking}

Motor cycle is a two wheel motorized vehicle. Due to convenience use of motor cycle increase rapidly. In our country mainly at Dhaka city motorcycle user expand hurriedly. According to BRTA registered motor cycle in Dhaka city is $3,11,071$. As there is no off-street parking facilities in our Dhaka city about all motor cycle user use free road way width for parking purpose. Sometimes they park where parking is proscribed. Authorize or un-authorized motor cycle parking are responsible for effective roadway width loss shown on the following table 3 . Also unauthorized motorcycle parking is shown on the figure 2 . 
Table 3. Reduction of roadway width for motorcycle.

\begin{tabular}{lllll}
\hline Route name & Width loss $(\mathbf{m})$ & Total Width $(\mathbf{m})$ & \%Width Loss & Average Width Loss \\
\hline Mirpur 1 - Technical & 2.50 & 12.20 & 20.49 & \\
Technical - Shyamoli & 1.65 & 11.27 & 14.64 & $16.56 \%$ \\
Shyamoli - Asadgate & 4.30 & 16.50 & 26.06 & \\
Asadgate - Dhanmondi27 & 2.35 & 16.53 & 14.22 & 7.40 \\
Dhanmondi27 - New market & 1.20 & 16.20 & & \\
\hline
\end{tabular}

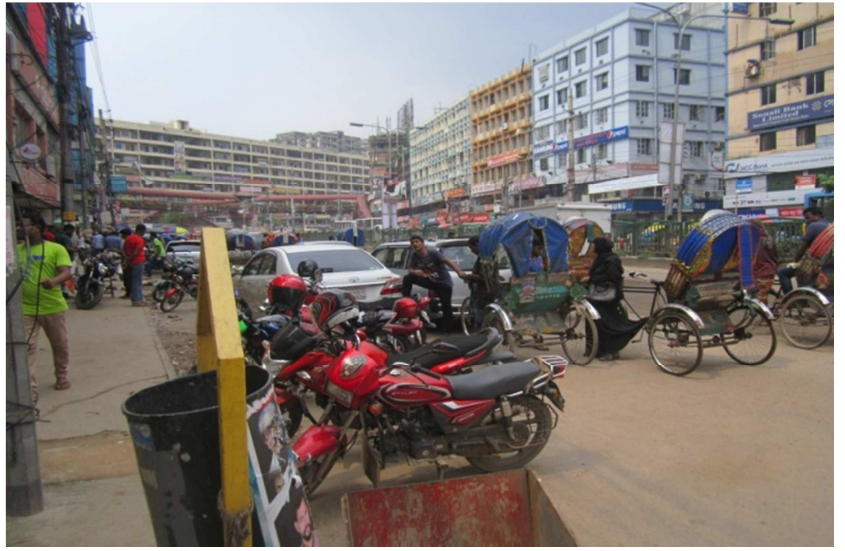

Figure 2. Illegal motor cycle parking on the road.

\subsubsection{Bus Parking}

Bus one of the most familiar mass transit systems in metropolitan Dhaka is mainly characterized by large bus, mini bus. Bus and minibus routes tend to be concentrated along the limited number of arterial roads, in a generally north-south orientation. Large buses are defined according to regulation as buses with more than 32 seats, but more generally large buses are considered to be ten (10) meters or more in length. The most significant recent change in the bus fleet composition is the increases in the number of large buses. According to BRTA number of Busses in our Dhaka city are 8694 up to June 2010. Mini buses are defined as buses with 15 to 30 seat capacity, excluding the driver. Most mini buses are around 8 meters in length, with locally manufactured bodies and Isuzu, Hino or Tata chassis and engines. The number of mini buses has increased rapidly since 2000. Current numbers are imprecise, but according to BRTA 8,405 mini buses are in operation in Dhaka, also around 2000 to 3000 are operating without permits or in contravention of allocated routes [4].

Table 4. Reduction of roadway width for Bus.

\begin{tabular}{llll}
\hline Route name & Width loss $(\mathbf{m})$ & Total Width $(\mathbf{m})$ & \% Width Loss \\
\hline Mirpur 1-Technical & 5.60 & 12.20 & 45.90 \\
Technical-Shyamoli & 4.86 & 11.27 & 43.12 \\
Shyamoli - Asad gate & 4.30 & 16.50 & 26.06 \\
Asadgate - New market & 5.50 & 16.53 & 33.27 \\
\hline
\end{tabular}

\subsubsection{Rickshaw Parking}

Rickshaws are three wheeled cycles called cycle rickshaws. It is manually operated giving door to door services to the passengers. The rickshaws normal carrying capacity is two passengers. One of the main causes of Dhaka's traffic jam is the unrestricted playing of rickshaws particularly on the main transport corridor. Reliable estimates of the non-motorized vehicle fleet are difficult to obtain. DCC (Dhaka City Corporation) limits the number of license issued to rickshaw owners to some 79,000. However, unofficial estimate claimed that the number of rickshaw playing in Dhaka is about 500,000 [4].

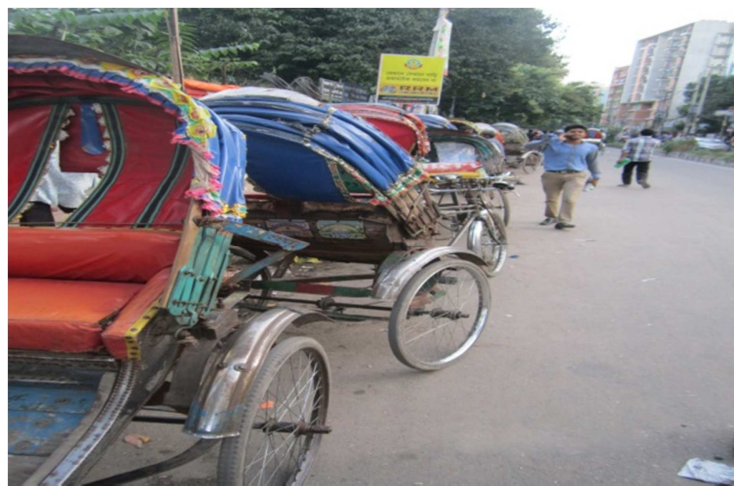

Figure 3. Illegal Rickshaw parking on the road.

Table 5. Reduction of roadway width for Rickshaw.

\begin{tabular}{llll}
\hline Route name & Width loss $(\mathbf{m})$ & Total Width $(\mathbf{m})$ & \% Width Loss \\
\hline Mirpur 1 - Technical & 3.15 & 12.20 & 25.82 \\
Technical - Shyamoli & 3.10 & 11.27 & 27.51 \\
Shyamoli - Asadgate & 2.90 & 16.50 & 17.58 \\
Asadgate - Dhanmondi27 & 2.56 & 16.53 & 15.49 \\
Dhanmondi27 -Newmarket & 2.95 & 16.20 & 18.21 \\
\hline
\end{tabular}




\subsubsection{Double Parking}

Double parking is a common phenomenon on the busy roads. It's a regular feature at Motijheel to Dainik Bangla, New market to science lab and FAkirapool to Arambag roads. For different types of Double parking effective roadway reduction is shown in the following table 6.

Table 6. Reduction of roadway width for Double Parking

\begin{tabular}{lllll}
\hline Route name & Type & Width loss (m) & Total Width (m) & \%Width Loss \\
\hline Mirpur 1 -Technical & C+R & 7.89 & 12.20 & 64.67 \\
Technical - Shyamoli & C+Mo & 7.65 & 11.27 & 67.88 \\
Shyamoli - Asadgate & C+C & 4.90 & 16.50 & 29.70 \\
Asadgate - Dhanmondi27 & C+Cn & 4.85 & 16.53 & 29.34 \\
Dhanmondi27 - Newmarket & Cn+R & 5.00 & 16.20 & 30.86 \\
\hline
\end{tabular}

Here, $\mathrm{C}=$ Private car, $\mathrm{Mo}=$ Motorcycle, $\mathrm{R}=$ Rickshaw, $\mathrm{Cn}=\mathrm{CNG}$.

\subsection{Different Types Of Stall}

\subsubsection{Tea Stall}

A tea stall is a small shop where ready tea is served to the customers. It mainly sits at railway or bus station. Besides, It is found at bazers, a factory or a launch ghat. But it's become common scenery that tea stalls are always available on road or footpath. As its stands on the road it takes some effective width of the road. Also customers, used furniture and waste of tea stalls are act as a side friction on the road.

Table 7. Reduction of roadway width for Tea stall.

\begin{tabular}{llll}
\hline Route name & Width loss $(\mathbf{m})$ & Total Width $(\mathbf{m})$ & \%Width Loss \\
\hline Mirpur 1 - Technicl & 1.60 & 2.80 & 57.14 \\
Technical - Shyamoli & 1.55 & 3.20 & 48.44 \\
Shyamoli - Asadgate & 2.22 & 3.11 & 71.38 \\
Asadgate - Dhanmondi27 & 1.25 & 2.50 & 50.00 \\
Dhanmondi27 - Newmarket & 1.80 & 2.56 & 70.31 \\
\hline
\end{tabular}

\subsubsection{Shirt, Pant and Belt Stall}

Retail trading activities on or besides the road are most popular in our Dhaka city. Cheapest rate of shirt, pant and belts attract pedestrian, day labor, workers and officials. Mainly middle class and lower middle class people are regular customer. At the time of buying and selling activity both buyers and sellers stand on the road, which disturb the frequent or free movement of vehicles. For this reason drivers try to sidestep these obstacles. Due to this propensity effective roadway width is reduced consequently roadway capacity. Following table 8 shows contribution on effective roadway width loss of these types of retail trading activity on our selected sites.

Table 8. Reduction of roadway width for Shirt, pant and belt stall.

\begin{tabular}{llll}
\hline Route name & Width loss $(\mathbf{m})$ & Total Width $(\mathbf{m})$ & \% Width Loss \\
\hline Mirpur 1 - Technical & 1.82 & 2.80 & 65.00 \\
Technical - Shyamoli & 1.20 & 3.20 & 37.50 \\
Shyamoli - Asadgate & 1.35 & 3.11 & 43.41 \\
Asadgate- Dhandmondi27 & 1.75 & 2.50 & 70.00 \\
Dhandmondi27- Newmarket & 2.12 & 2.56 & 82.81 \\
\hline
\end{tabular}

\subsubsection{Fruits Stall}

Among different types of retail activity, fruits stall is frequent. Fruits stall may be classified as permanent or temporary. Permanent means stalls which stay for long time also it occupies some place of footpath whereas temporary defined as stalls which stay for short period of time and moveable. Contributions of effective road way width loss of different fruits stall are shown in table 9.

Table 9. Reduction of roadway width for Fruit stall.

\begin{tabular}{llll}
\hline Route name & Width loss $(\mathbf{m})$ & Total Width $(\mathbf{m})$ & \% Width Loss \\
\hline Mirpur 1 - Technical & 1.84 & 2.80 & 65.71 \\
Technical - Shyamoli & 1.50 & 3.20 & 46.87 \\
Shyamoli - Asadgate & 2.23 & 3.11 & 71.70 \\
Asadgate- Dhandmondi27 & 2.12 & 2.50 & 84.80 \\
Dhandmondi27- Newmarket & 2.00 & 2.56 & 78.12 \\
\hline
\end{tabular}




\subsubsection{Other Stall}

Though tea, fruits, shirt, pant and belt stalls are common at different street, another types of retail activity are found also. These types of stalls are not frequently found at everywhere. From field observation we find lottery ticket seller, bus counter, Peanut stall, small hotel etc as side frictions on the road. Among these lottery ticket and peanut seller are movable. But small hotel and Bus counter are fixed at a place. Mainly cake is the selling product of this small hotel. table 10 shows the contribution of effective width losses due to these types of stall.

Table 10. Reduction of roadway width for different stalls.

\begin{tabular}{lllll}
\hline Route & Stall & Width loss (m) & Total Width (m) & \% Width Loss \\
\hline Mirpur 1 - Technical & Bus counter & 3.29 & 12.20 & 26.97 \\
Technical - Shyamoli & Bus counter & 3.18 & 11.27 & 28.22 \\
Shyamoli - Asadgate & Peanut seller & 1.20 & 16.50 & 7.27 \\
Asadgate-Dhanmondi27 & Small hotel & 3.35 & 16.53 & 20.27 \\
Dhanmondi27-Newmarket & Small hotel & 3.75 & 16.20 & $21.18 \%$ \\
\hline
\end{tabular}

\subsection{Scrap of Stalls}

Scraps of different stalls obstruct the free movement of vehicles. Drivers and pedestrian always try to by-pass these types of obstacle. Due to this tendency effective roadway width is reduced. Among different types of scraps scrap from fruit stalls is dominating. Also scrap is found from shirt, pant or belt stall.

Table 11. Reduction of roadway width for scrap of stalls.

\begin{tabular}{lllll}
\hline Route name & Width loss $(\mathbf{m})$ & Total Width $(\mathbf{m})$ & \%Width Loss & Average Width Loss \\
\hline Mirpur 1 -Technical & 1.85 & 12.20 & 15.16 & 16.86 \\
Technical - Shyamoli & 1.90 & 11.27 & 16.67 & $14.61 \%$ \\
Shyamoli - Asadgate & 2.75 & 16.50 & 7.62 & 16.72 \\
Asadgate - Dhanmondi27 & 1.26 & 16.53 & 16.20 & \\
Dhanmondi27 - Newmarket & 2.71 & & \\
\hline
\end{tabular}

\subsection{Electric Pole}

A utility pole is a pole use to support overhead power lines and various other public utilities, such as cable, fiber optic cable and related equipment such as transformers and street lights. In the United States, the National Electrical Safety Code, published by the Institute of Electrical and Electronics
Engineers (IEEE), sets the standards for construction and maintenance of utility poles and their equipment but it's hardly found in our Dhaka city. It's often found that electric pole passes by the road, hence occupation of roadway width. Due to this occupation vehicles loose effective road width consequence is reduction of roadway capacity.

Table 12. Reduction of roadway width for electric pole.

\begin{tabular}{llll}
\hline Route name & Width loss (m) & Total Width (m) & \%Width Loss \\
\hline Mirpur - Technical & 1.48 & 12.20 & 12.13 \\
Technical - Shyamoli & 1.55 & 11.27 & 13.75 \\
Shyamoli - Asadgate & 1.49 & 16.50 & 9.03 \\
Asadgate - Dhandmondi27 & 2.10 & 16.53 & 12.70 \\
Dhandmondi27 - New market & 1.85 & 16.20 & 11.42 \\
\hline
\end{tabular}

\subsection{Waste and Dustbin}

A dustbin or waste container is a container for temporarily storing waste, and is usually made out of metal or plastic. Most of the developed countries keep dustbin besides the road at outer thinking. But anyone can easily noticed dustbin on the road network of Dhaka city. Due to health concern and aesthetically unpleasant people try to avoid it. Concern authority, Dhaka City Corporation has no headache to provide smooth and pleasant environment to the road user. It occupies massive amount of road length and create bottleneck for that particular section at peak hour [11].

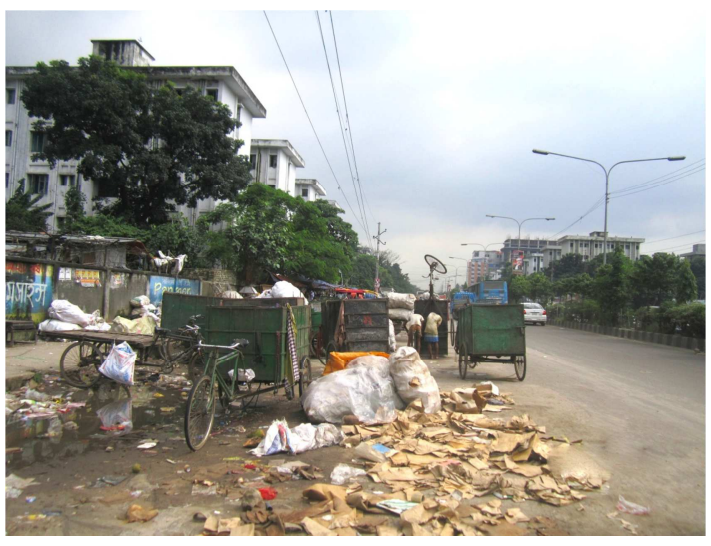

Figure 4. Dustbin on the road. 
Table 13. Reduction of roadway width for waste and dustbin.

\begin{tabular}{lllll}
\hline Route name & Width loss (m) & Total Width $(\mathbf{m})$ & \%Width Loss & Average Width Loss \\
\hline Mirpur 1 -Technical & 4.25 & 12.20 & 34.84 & \\
Technical - Shyamoli & 3.25 & 11.27 & 28.84 & $24.13 \%$ \\
Shyamoli - Asadgate & 2.56 & 16.50 & 15.52 & \\
Asadgate - Dhanmondi27 & 3.59 & 16.53 & 21.72 & 19.75 \\
Dhanmondi27 - Newmarket & 3.20 & 16.20 & & \\
\hline
\end{tabular}

\subsection{Police Barricades}

To prevent illegal activities on the road and also to reduce traffic congestion Police force always try to create obstacle on road. They take various preventive actions. Among which police barricades are common. Police barricades are so commonly used that most of the time they are common at roadway. Due to blockage of road effective roadway width is reduced. Following table 14 shows the feature.

Table 14. Reduction of roadway width for police barricades.

\begin{tabular}{lllll}
\hline Route name & Width loss (m) & Total Width $(\mathbf{m})$ & \%Width Loss & Average Width Loss \\
\hline Mirpur 1 - Technical & 2.30 & 12.20 & 18.85 & $24.99 \%$ \\
Technical - Shyamoli & 3.25 & 11.27 & 28.84 & \\
Asadgate - Dhanmondi27 & 4.50 & 16.50 & 27.27 & \\
\hline
\end{tabular}

\subsection{Roadside Cutting}

Roadside cutting is a common trend in our Dhaka city. Different government organizations cut the roadside several times to pass their utility line. Among them WASA, DPDC, BTCL, DCC and Titas gas companies are common. Due to lack of coordination among them after the complete of one work another interested group starts their work. Due to this cutting activity huge amount of effective roadway width is reduced.

Table 15. Reduction of roadway width for roadside cutting activity.

\begin{tabular}{llll}
\hline Route name & Width loss $(\mathbf{m})$ & Total Width $(\mathbf{m})$ & \%Width Loss \\
\hline Technical - Shyamoli & 3.50 & 11.27 & 31.06 \\
Shyamoli - Asadgate & 3.20 & 16.50 & 19.39 \\
\hline
\end{tabular}

\section{Conclusion and Recommendation}

\subsection{General}

With the increasing demand resulting from the population explosion and infrastructural and economic mutiny in the world, it is a great concern and required urgent awareness for all to prepare capital city as a high potential richly developed sustainable city for the restraining of forthcoming demand of the 21 st century as a mega city. But for the misunderstanding of the real problems of this city, every approach has taken the city to the odd condition day by day. In every step, to overcome the problem, the authorities are providing slowly solution without a long term vision which is becoming an extra burden on the city infrastructure. That is, the city is developed with the decaying growth. If these conditions further continue for a years, there will not be any option to recover or renew the condition of the city and it will become a dead city and eventually the city will have to be abandoned. Before the starting of further step, authority will have to identify the root causes of the problem and inherent weaknesses of the city.
This chapter has presented the study findings as well as point out the inherent weaknesses of the city particularly related to the loss of effective width of Dhaka city road network also reduction of roadway capacity. It is expected that the findings of this research would immensely help the city authorities, policy makers, professionals, academicians, planners, developers as well as civil society to identify the root cause of the side friction problems also contribution of these factors at traffic congestion.

\subsection{Parking on the Road}

Efficient parking system provides harmonious vehicular movement. From off-street and on-street parking first one is very efficient concern to traffic congestion and roadway capacity reduction. But the second one is responsible reduction of roadway capacity. From field observation among different types of single parking car parking is frequent at commercial areas but bus pas parking occupies maximum road width. At some roads double parking is a serious headache at occupies maximum amount of roadway width. Percent of effective roadway width loss due to different types of parking are reflected at figure 5 . 


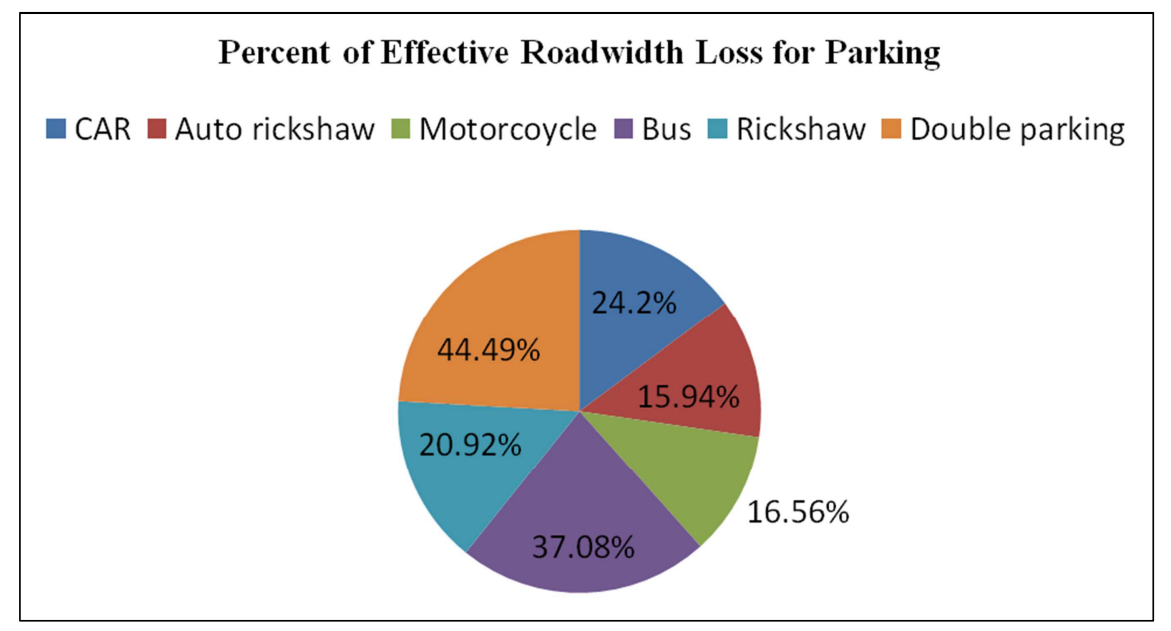

Figure 5. Percent of effective roadway width loss only for Parking.

\subsection{Stalls on the Road}

Different types of stalls on the road are another common trends in the Dhaka city. Mainly lower class people include with this. These retail activities may be temporary or permanent. Among various types of stalls on the road tea stall, shirt, pant and belt stall, Fruits stall and other temporary types of stalls are common. Due to different types of stall on an average 13 to 18 percent of effective roadway width is reduced. Contributions of these stalls on effective roadway width are reflected at figure 6.

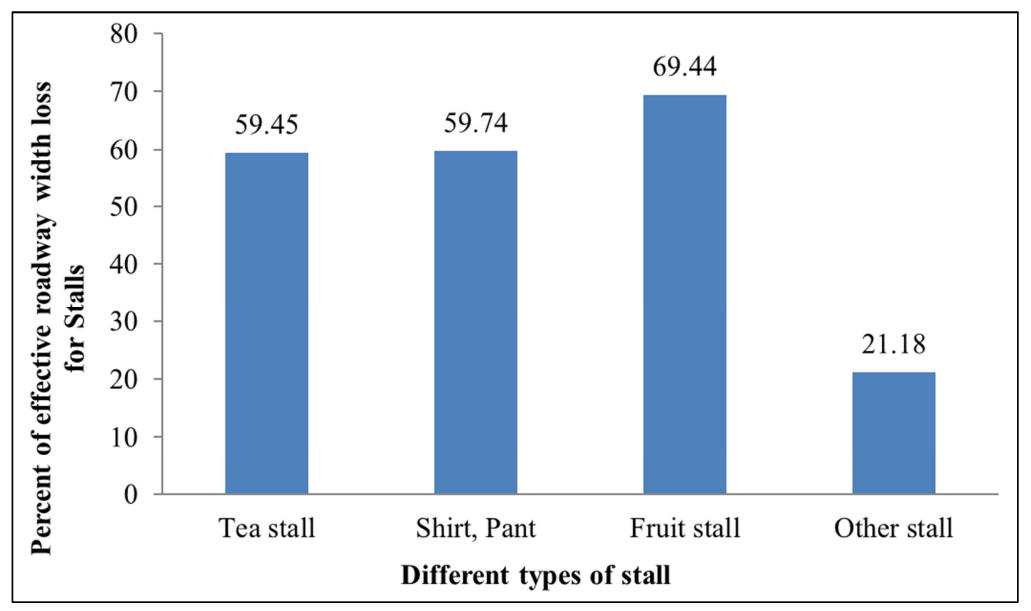

Figure 6. Percent of effective roadway width loss only for Stalls on the road.

\subsection{Overall View}

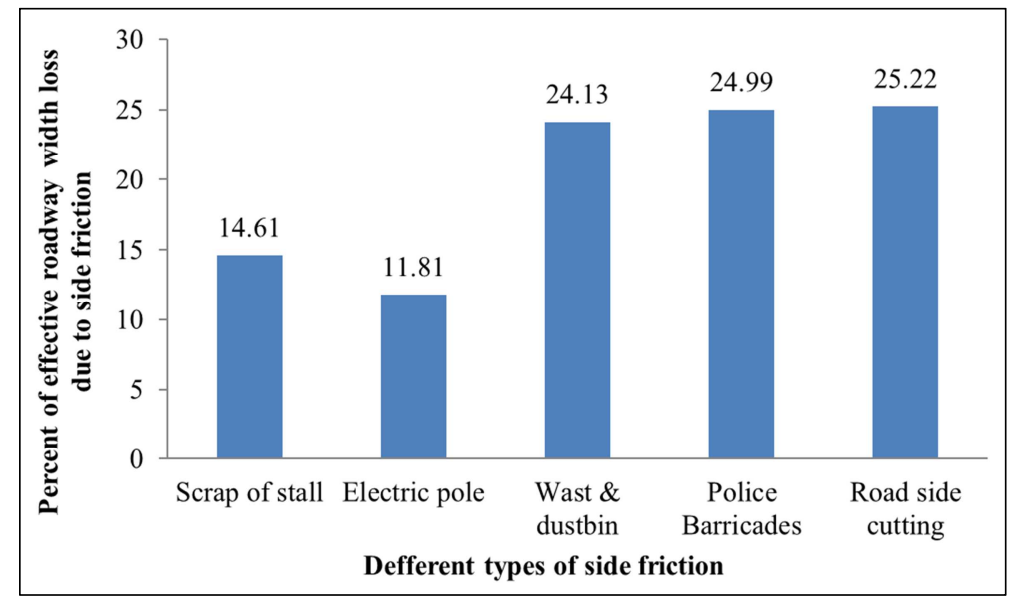

Figure 7. Percent of effective roadway width loss due to side friction. 
Among different types of side frictions parking, stalls on the road, scraps of stall, electric pole, waste and dustbin, police barricades, roadside cutting activity and increasing footpath width are analyzed in the context of effective roadway width loss. Before widening of the road we must provide special concern to the output of this analysis. It is found that on an average 12 to 29 percent of effective roadway width is reduced due to different side friction shown in figure 7.

\subsection{Roadway Capacity Reduction}

Capacity describes about the physical amount of vehicle and passengers a road can afford. It doesn't depend on the total number of vehicle demanding service. On the other hand, it depends on traffic conditions, roadway width geometry design and so on. It varies with respect to time and position. At this research concentration has been given only to reduction of roadway width not to roadway capacity. But we know with the reduction of roadway width roadway capacity is reduced. So assuming there is a linear relationship between roadway capacity and effective roadway width. From this assumption it can be qualitatively said that due to side frictions on the road roadway capacity is reduced enormously as well as level of service which leads to traffic congestion.

\subsection{Recommendation}

To resolve the side friction associated with the road network following remedies should be taken as per as possible.

i. Provision should be provided for on-street parking. Therefore, off-street parking needs to be created and at the same time. Restriction on on-street parking should be strictly enforced for certain periods of the day, and on certain days of the week.

ii. Government should give subsidy if the buses are owned by a company, so that they are able to maintain a bus depot for parking of their buses. This will reduce parking the bus on the road and ensure through movement of other vehicles.

iii. Non-motorized vehicle (rickshaws, etc.) should be banned from all major roads to achieve faster movement of vehicles leading to higher productivity.

iv. As private car parking is frequent restriction should provide on the import of vehicles for private use, but import of buses and mini-buses should be encouraged.

v. Law enforcement agencies should aware about illegal parking on the road.

vi. To remove retail activities on the road DCC should come forward.

vii. Though removal of Hawkers from roadside becomes a political issue so political leader should concern about the topic.

viii. Proper solution should be given to clean the roadway surface from waste and dustbin. ix. To ensure free and harmonious movement of pedestrian footpath should free from hawkers and other types of retail activities.

x. Pedestrian should provide proper information and education as they don't walk along the roadway.

xi. Seller should aware as they don't through the scraps of their stall on the road.

xii. Different government agencies should co-ordinate among them at the time road work.

xiii. Above all authorized agency and government should take proper steps and plan to reduce side friction on the road network.

\section{Limitation of the Study and Scope for Future Study}

In a summarized way, it was seems that the study area and topics covered a wide range area and in depth evaluation to fulfill the objectives in this topics was a complicated and difficult issue due to the scarcity of data, manpower, resource, expertise and time constrains. To overcome these difficulties, the study was elaborated in breath but in depth it is shallow. If the following important aspects and issues could have been considered in this research study, it would have been more comprehensive and complete.

As no study has found related to this topics in a developed country like ours personal judgment has to apply in many case. Besides, no secondary data has found at different government agencies related to side friction. Analysis has done by using only primary data. Study is performed only for commercial areas. Qualitative reduction of roadway capacity is shown but it can be provide quantity. Analysis has done only for the factors which are temporary stands on the road. No analysis is shown for the following cases such as: side road entries, effect of NMV on traffic stream, walking of pedestrian and so on.

Taking into consideration of above issues and items, in future sector wise studies may be conducted to have more authentic, reliable, definite, comprehensive and wide-ranging findings and for subsequent recommendations and decisions.

\section{References}

[1] Chiguma Masatu, L. M. (2007), "Analysis of side friction impacts on urban road links; Case study Dar-es-salaam", Royal Institute of Technology, Stockholm, Sweden.

[2] Bhuyan M. H. (2006), "Study on Transport Deficiencies at Kalabagan Area of Dhaka City", Bachelor of Science in Civil Engineering, Department of Civil Engineering, Bangladesh University of Engineering and Technology (BUET), Dhaka, Bangladesh.

[3] Rahman M. (2001), "Institutional Issues", Reforming Dhaka City Management, Bangladesh Centre for Advanced Studies, Dhaka. 
[4] STP (2014), "Strategic Transport Plan (STP) for Dhaka, Final Report, 2006", Dhaka Transport Coordination Board (DTCB), Dhaka.

[5] Mildner G., Strathman J. and Bianco M. (1997), "Parking Policies and Commuting Behavior," Transportation Quarterly, Vol. 51, No. 1, Winter 1997, pp. 111-125.

[6] Ahsan, H. M. (1990), "A Study of Mass Transit in Metropolitan Dhaka", M. Sc. Thesis Department of Civil Engineering, Bangladesh University of Engineering and Technology (BUET), Dhaka, Bangladesh.

[7] Mahmud, S. M. S (2009), “ Identifying the deficiencies of land use -Transport development in Dhaka city ", M. Sc Thesis, Department of civil Engineering, Bangladesh University of Engineering and Technology.

[8] Choudhury, Kamaluddin, A. K. M. (1985), "Land use planning in Bangladesh", National institute of Local Government, Dhaka, 1985.

[9] DCC (2006), "Profile of Dhaka City Corporation", yearly publication, published by Dhaka City Corporation (DCC), January 2006.

[10] DCC (2004), "Profile of Dhaka City Corporation", yearly publication, published by Dhaka City Corporation (DCC), January 2004.

[11] Habib M. H. \& Mitro S. (2004), "Dhaka transport problem", Department of Urban and Regional Planning (URP), Bangladesh University of Engineering and Technology (BUET), Dhaka, Bangladesh.
[12] Hashem M. (2001), "Trends of Development in Dhanmondi Residential Area of Dhaka City", MURP, Department of Urban and Regional Planning (UPR), Banglades University of Engineering and Technology (BUET), Dhaka, Bangladesh, April 2001

[13] Islam N. (2001), "Transportation in Dhaka City", Urbanization, Urban Planning and Development and Urban Governance, A reader for student, Centre of Urban Studies, April 2001, pp 86-96.

[14] Bang K-L., Heshen A. (2000). 'Development of Capacity Guidelines for Road links and Intersections for Henan and Hebei Provinces, PRC', Transportation Research E-C018, Fourth International Symposium on Highway Capacity Proceedings, Maui, Hawaii page 288-298.

[15] Black J. A., Westerman H. L., Blinkhorn L. and McKittrick J., (1988), 'Land use along arterial roads: friction and impact', The Environmental Planning and Management Series, School of Town Planning, University of New South Wales.

[16] BWDB (2006), "Updating/Upgrading the Feasibility Study of Dhaka Integrated Flood Control Embankment cum Eastern Bypass Road Multipurpose Project", Draft Final Report by BWDB, 31 May 2006.

[17] Tom V. Mathew and K Ravishankar, (2011), "Car following behavior in traffic having mixed vehicle-types Transportation Letters", International Journal of Transportation Research, 3 (2), 109-123. 